OPEN ACCESS

Edited by:

Umberto Volpe,

Marche Polytechnic University, Italy

Reviewed by:

Imran Gökçen Yilmaz Karaman, Eskişehir Osmangazi University, Turkey

Renato de Filippis,

University of Catanzaro, Italy

*Correspondence:

Yan Liu

hakunaly@163.com

JianLi Wang

jianli.wang@dal.ca

Debiao Liu

biao12131415@aliyun.com

these authors have contributed equally to this work and share first

authorship

Specialty section: This article was submitted to

Public Mental Health,

a section of the journal

Frontiers in Public Health

Received: 06 November 2021

Accepted: 01 February 2022

Published: 02 March 2022

Citation:

Zhu J, Li B, Hao F, Luo L, Yue S,

Zhai J, Chen M, Liu Y, Liu D and

Wang J (2022) Gender-Specific Related Factors for Suicidal Ideation

During COVID-19 Pandemic Lockdown Among 5,175 Chinese Adolescents.

Front. Public Health 10:810101. doi: 10.3389/fpubh.2022.810101

\section{Gender-Specific Related Factors for Suicidal Ideation During COVID-19 Pandemic Lockdown Among 5,175 Chinese Adolescents}

\author{
Jin Zhu ${ }^{1,2,3,4 \dagger}$, Baohua $\mathrm{Li}^{5 \dagger}$, Fengcheng Hao ${ }^{6 \dagger}$, Linlin Luo ${ }^{4,7 \dagger}$, Song Yue ${ }^{4,7}$, Jinguo Zhai ${ }^{4,5}$, \\ Min Chen ${ }^{4,5}$, Yan Liu ${ }^{1,2,3,4 *}$, Debiao Liu ${ }^{4 *}$ and JianLi Wang ${ }^{4,8 *}$
}

${ }^{1}$ Shandong Key Laboratory of Behavioral Medicine, School of Mental Health, Jining Medical University, Jining, China, ${ }^{2}$ Shandong Collaborative Innovation Center for Diagnosis and Treatment and Behavioral Interventions of Mental Disorders, Institute of Mental Health, Jining Medical University, Jining, China, ${ }^{3}$ Center of Evidence-Based Medicine, Jining Medical University, Jining, China, ${ }^{4}$ School of Mental Health, Jining Medical University, Jining, China, ${ }^{5}$ Daizhuang Hospital of Shandong Province, Jining, China, ${ }^{6}$ Zoucheng People's Hospital, Zoucheng, China, ${ }^{7}$ Department of Pathology, School of Basic Medicine, Weifang Medical University, Weifang, China, ${ }^{8}$ Department of Community Health and Epidemiology, Faculty of Medicine, Dalhousie University, Halifax, NS, Canada

Background: Suicide was an urgent issue during the pandemic period in adolescents. However, few studies were focused on suicide during the coronavirus disease 2019 (COVID-19) pandemic lockdown.

Methods: An online survey was conducted among 5,175 Chinese adolescents from June 9th to 29th in 2020 to investigate the prevalence of suicidal ideation (SI) during COVID-19 pandemic lockdown. A gender-specific stepwise logistic regression model was used. All analyses were performed with STATA 15.0.

Results: About 3\% of the participants had reported having SI during the COVID-19 pandemic lockdown period. The prevalence of female SI (3.64\%, 95\% Cl: 2.97-4.45\%) was higher than that of males $(2.39 \%, 95 \% \mathrm{Cl}: 1.88-3.05 \%)\left(\chi^{2}=6.87, p=0.009\right)$. Quarreling with parents [odds ratio $(\mathrm{OR})=9.73,95 \% \mathrm{Cl}$ : 5.38-17.59], insomnia (OR $=5.28,95 \% \mathrm{Cl}: 2.81-9.93)$, previous suicide attempt history $(\mathrm{OR}=3.68,95 \% \mathrm{Cl}$ : 1.69-8.03), previous SI history (OR $=2.81,95 \% \mathrm{Cl}$ : 1.30-6.06), and feeling depressed during pandemic lockdown $(\mathrm{OR}=2.26,95 \% \mathrm{Cl}$ : $1.22-4.18)$ were positively associated with the males' SI. However, having emptiness inside (OR = 4.39, 95\% Cl: 2.19-8.79), quarreling with parents $(\mathrm{OR}=3.72,95 \% \mathrm{Cl}: 2.16-6.41)$, insomnia $(\mathrm{OR}=3.28,95 \%$ $\mathrm{Cl}: 1.85-5.80)$, feeling anxious ( $\mathrm{OR}=2.62,95 \% \mathrm{Cl}$ : 1.46-4.70), and longing for father's emotional warmth $(\mathrm{OR}=0.38,0.20-0.72)$ were associated mostly with females' SI.

Conclusions: Female adolescents, who felt emptiness from their families and their fathers' emotional warmth, were at much higher risk of having SI during COVID-19 lockdown. We must specify a suicide prevention policy and interventions for adolescents in the pandemic crisis based on gender gaps.

Keywords: adolescents, COVID-19 pandemic lockdown, suicidal ideation, gender differences, predictive factor 


\section{INTRODUCTION}

Suicide has become the second leading cause of death among young people aged 15 to $29(1,2)$, with a rate of 4.57 per 100,000 (3). It is well recognized that suicidal ideation (SI) is an important predictor of suicide death (4). A meta-analysis showed that the prevalence of SI was $28 \%$ in adolescents up to 25 years (5). Factors such as negative life experiences (e.g., childhood abuse, bullying), unhealthy behaviors (e.g., smoking, alcohol abuse, poor parental relationships), psychological factors (e.g., low emotional support, low self-esteem, impulsivity), and physical illnesses (e.g., HIV, insomnia, chronic illness) could contribute to the occurrence of SI (6-16). However, there is a significant gender difference in suicide deaths between men and women; the suicide death rate of men is higher than that of women (17).

After the coronavirus disease 2019 (COVID-19) pandemic was announced by WHO on March 11, 2020 (18), there were over 304 million confirmed cases and over 5.4 million deaths until January 9, 2022 (19). Each government has responded quickly and has adopted necessary positive measures after the pandemic, including advocating quarantine at home, wearing masks, social distancing, etc., $(20,21)$. However, subsequent repeated home isolation policy might have a profound impact on people's mental health. The prevalence of mental health problems has become much higher during the COVID-19 pandemic lockdown period, including suicide issues (22-26). However, the influence of COVID-19 on suicidal ideation and the gender differences in adolescents have not been well-studied.

We conducted a cross-sectional online survey to explore the prevalence of SI during the COVID-19 pandemic lockdown period in Chinese adolescents and to explore gender-specific correlated factors for SI.

\section{METHODS}

\section{Study Setting and Data Collection Procedure}

This study was conducted in five cities/counties in Shandong Province, China, between June 9 and 29, 2020, when children and adolescents just went back to school after the COVID-19 pandemic lockdown (26). An online questionnaire survey (www.wjx.cn) was used to collect adolescents' general information, lifetime severe traumatic events, parenting style, and the specific status during the COVID-19 pandemic lockdown period. To control the research quality of the survey and to avoid repeated answers, the IP address of smartphones and computers were only accepted once. Two independent researchers checked the saved dataset separately.

The total numbers of the aimed primary and middle school students in target areas were 9,500 and 5,331 students (response rate $=56.12 \%$ ), respectively, who completed the online survey. The inclusion criteria were as follows: (1) voluntary participation in the study and has signed the informed consent form (participants under the age of 18 need the consent of the guardian; (2) No major physical diseases or mental disorders; and (3) Completed the questionnaire completely without a large number of blank questions. Exclusion criteria were: (1) No informed consent has been signed; (2) Suffering from major physical diseases or mental disorders; (3) The questionnaire was not completed.

Among the 5,331 questionnaires, 5,175 were available (available rate $=97.07 \%$ ). All surveys were conducted anonymously, and the privacy of the participants was respected. We obtained informed consent through the parents of the participants and the consent of the participants themselves.

The study protocol was approved by the Medical Ethics Committee of Jining Medical University (JNMC-2020-KY-004).

\section{Measurements}

The Chinese version of the Egna Minnen av Barndoms Uppfostran (EMBU) was used to estimate the parenting style of the adolescents $(27,28)$. It has 66 questions including six types $s$ of parenting styles by fathers (emotional warmth, punishment, favoring subject, over-interference, rejection, and overprotection) and five types of parenting styles by mothers (emotional warmth, punishment, favoring subject, rejection, over-interference, and overprotection). The EMBU demonstrated a high internal consistency in Chinese adolescents (28). In this study, if the score exceeded the mean score, we considered that the parenting to the participants presented the tendency in this dimension.

Severe lifetime traumatic events were measured by 13 specific questions. For example, "Have you ever experienced the deaths of your parents?", "Have you ever experienced severe physical illness?", "Have you ever been bullied at school?", and "Have you ever had suicidal ideation or suicide attempt? etc."? Participants needed to answer yes or no to each question.

Suicidal ideation was measured by asking "Have you ever had suicidal ideation during COVID-19 pandemic lockdown?" and the responses were categorized as "yes or no."

Feeling depressed, feeling anxious, and having emotional emptiness were measured by the exact question as: "Have you ever had depressed mood during the COVID-19 pandemic lockdown period?", "Have you ever had an anxious mood during the COVID-19 pandemic lockdown period?", and "Do you often feel empty inside ${ }_{i}$. In addition, we also investigated the participants' basic demographic characteristics, such as age, gender, grade, being an only-child, and the specific status during the COVID-19 pandemic.

\section{Statistical Analysis}

The sample size needed in this study was calculated by the sample size calculation formula of epidemiological cross-sectional study. The formula was as follows: $\mathrm{n}=\frac{Z_{1-\frac{\alpha}{2}}^{2} \pi(1-\pi)}{\delta^{2}}$ (where $\pi$ was the population rate and $\delta$ was the allowable error). Based on Nock's findings, the prevalence rate (12.1\%), $\alpha=0.05$, and $\delta=0.02$ (29). According to the principle of doubling the sample size of the cluster sampling, the number of the aimed minimum sample size was 2,025.

All analyses were performed with STATA 15.0 version (30). The statistical significance was set at the level of $\alpha=0.05$, and $P<0.05$ was considered the statistical significance. The $t$-test or $\chi^{2}$ test is used to analyze differences in continuous variables 
TABLE 1 | Characteristics of 5,175 participants and frequencies (\%).

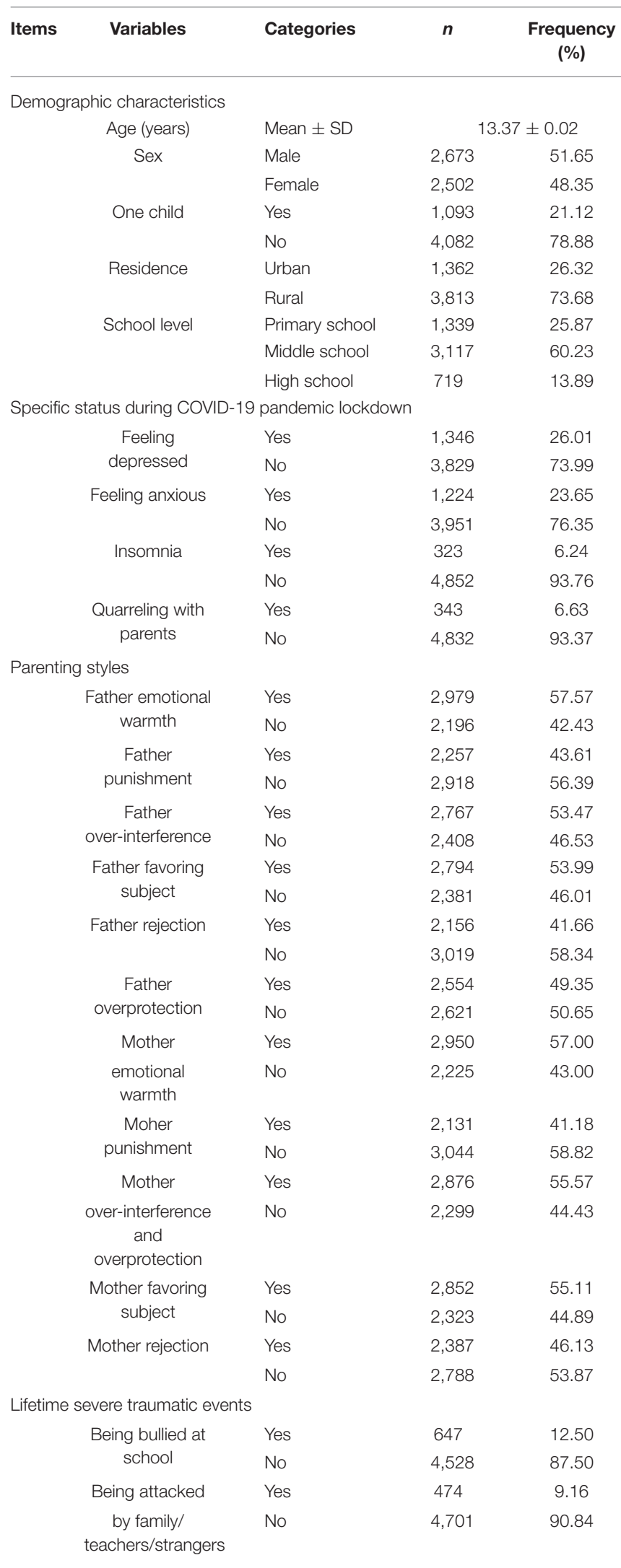

(Continued)
TABLE 1 | Continued

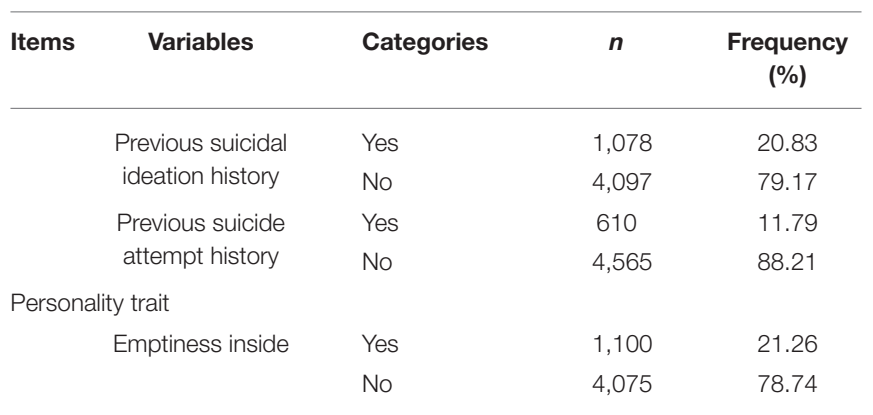

or categorical variables to explore gender, urban and rural differences in demographic characteristics, or other variables. The prevalence of suicidal ideation during COVID-19 and associated $95 \%$ CI were estimated. Logistic regression was carried out to examine the relationships between the potentially related factors and the suicidal ideation. A gender-specific stepwise logistic regression was used to determine the final models. The odds ratio (OR) and their 95\% CI were reported.

\section{RESULTS}

The sample population of our survey was randomly distributed in five counties in two cities, including the 8th grades. Finally, there were 5,175 available questionnaires. The characteristics of participants are displayed in Table 1. There were 2,673 (51.7\%) males and 2,502 (48.3\%) females. Among these, 3,813 (73.7\%) were from rural and 1,362 (26.3\%) were from urban. The age range was 9-19 years old and the mean (SD) of participants' age was 13.38 (1.56\%). Most of the participants were junior high school students $(60.2 \%)$, others were in primary school (25.9\%), and senior high school (13.9\%). There were 3,842 (74.2\%) participants who lived with parents, 197 (3.8\%) lived only with their father, and $816(15.8 \%)$ lived only with their mother. Most of the participants have at least one sibling (78.9\%). Besides, 1,346 (26\%) felt depressed and 1,224 (23.7\%) felt anxious. Among 5,175 students, 155 (3\%) had suicidal ideation during the COVID-19 pandemic lockdown. Among 2,673 male and 2,502 female participants, there are $64(2.39 \%)$ males with suicidal ideation, 2,609 (97.61\%) males without suicidal ideation, 91 (3.64\%) females with suicidal ideation, and 2,411 (96.36\%) females without suicidal ideation. The characteristics of 5,175 participants by sex and suicidal ideation were displayed in Table 2.

The prevalence of suicidal ideation during the COVID19 pandemic lockdown of all the participants was $3 \%$. The prevalence of suicidal ideation in female participants $(3.64 \%)$ was higher than that in males $(2.39 \%)\left(\chi^{2}=6.87, P=0.009\right)$. There was no significant difference in the prevalence of suicidal ideation between adolescents in different grades $\left(\chi^{2}=2.33, P=0.312\right)$, one-child family structure $\left(\chi^{2}=0.06, P=0.801\right)$, and residence areas $\left(\chi^{2}=0.61, P=0.436\right)$.

The correlations between the related factors and the suicidal ideation during the COVID-19 pandemic lockdown 
TABLE 2 | Characteristics of 5,175 participants by sex and suicidal ideation.

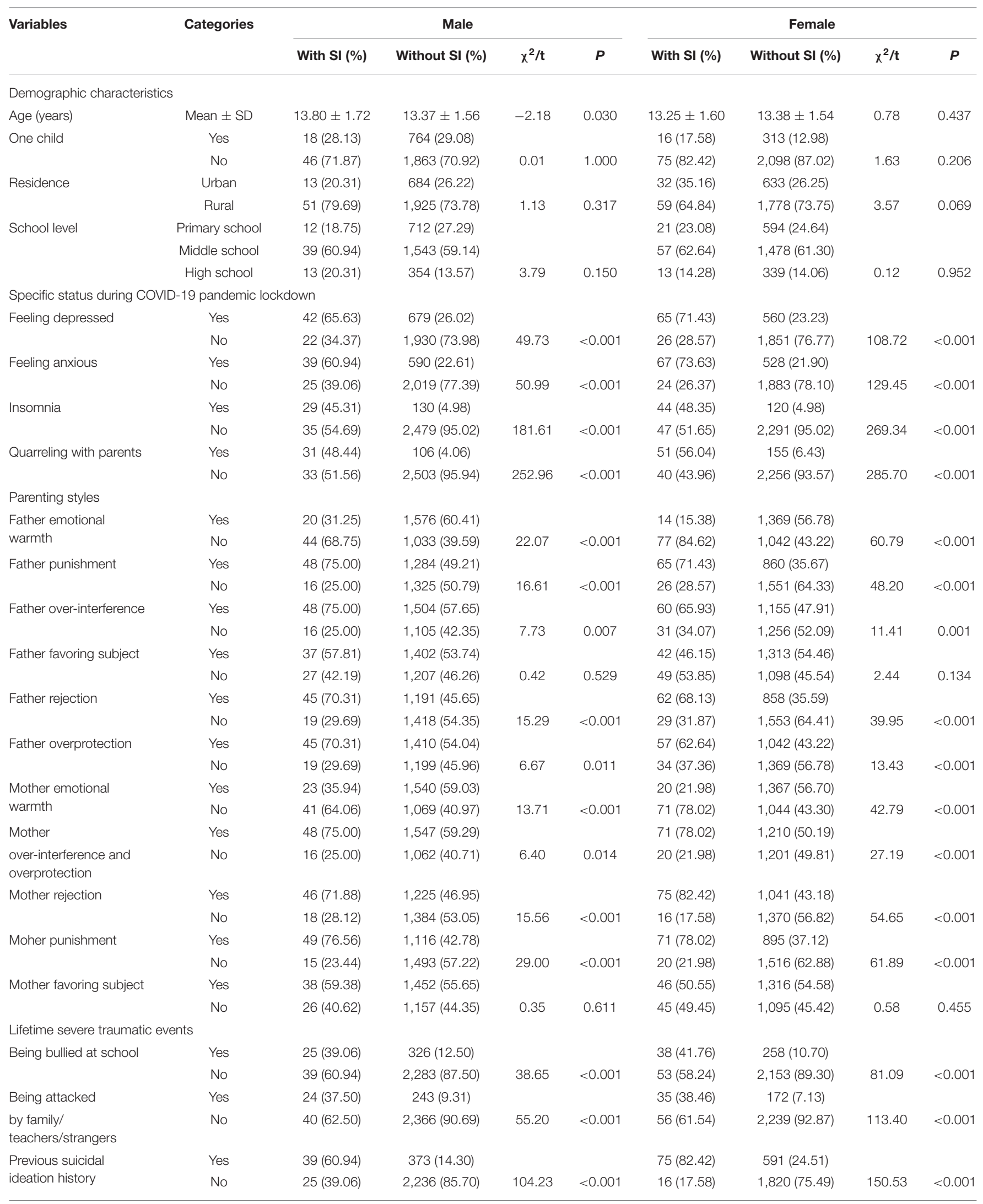


TABLE 2 | Continued

\begin{tabular}{|c|c|c|c|c|c|c|c|c|c|}
\hline \multirow[t]{2}{*}{ Variables } & \multirow[t]{2}{*}{ Categories } & \multicolumn{4}{|c|}{ Male } & \multicolumn{4}{|c|}{ Female } \\
\hline & & With SI (\%) & Without SI (\%) & $\chi^{2 / t}$ & $\boldsymbol{P}$ & With SI (\%) & Without SI (\%) & $x^{2 / t}$ & $P$ \\
\hline \multirow{2}{*}{$\begin{array}{l}\text { Previous suicide } \\
\text { attempt history }\end{array}$} & Yes & $31(48.44)$ & $199(7.63)$ & & & 65 (71.43) & 315 (13.07) & & \\
\hline & No & $33(51.56)$ & $2,410(92.37)$ & 132.29 & $<0.001$ & $26(28.57)$ & 2,096 (86.93) & 231.89 & $<0.001$ \\
\hline \multirow{2}{*}{$\begin{array}{l}\text { Personality trait } \\
\text { Emptiness inside }\end{array}$} & Yes & $33(51.56)$ & 439 (16.83) & & & 78 (85.71) & $550(22.81)$ & & \\
\hline & No & $31(48.44)$ & $2,170(83.17)$ & 51.84 & $<0.001$ & $13(14.29)$ & $1,861(77.19)$ & 184.56 & $<0.001$ \\
\hline
\end{tabular}

were analyzed by univariate logistic regression (Table 3). Demographic characteristics (age), specific status during COVID-19 pandemic lockdown (feeling depressed, feeling anxious, insomnia and quarreling with parents), parenting styles (father's emotional warmth, father's punishment, father's over-interference, father's rejection, father's overprotection, mother's emotional warmth, mother's punishment, mother's over-interference and overprotection, and mother's rejection), and a lifetime of severe traumatic events (being bullied at school, being attacked by family/teachers/strangers, previous suicidal attempt history, previous suicide attempt history, and having emptiness inside) were associated with suicidal ideation in the participants during COVID-19 pandemic lockdown. Sex-specific results are in Table 3.

The stepwise logistic regression results for suicidal ideation were shown in Table 4. Quarreling with parents $(\mathrm{OR}=9.73$, 95\% CI: 5.38-17.59), insomnia (OR $=5.28,95 \%$ CI: 2.81-9.93), previous suicide attempt history (OR $=3.68$, 95\% CI: $1.69-$ $8.03)$, previous suicidal ideation history $(\mathrm{OR}=2.81,95 \% \mathrm{CI}$ : $1.30-6.06$ ), and feeling depressed (OR $=2.26$, 95\% CI: $1.22-$ 4.18) were associated with the SI during COVID-19 lockdown in male participants. In female participants, having emptiness inside $(\mathrm{OR}=4.39,95 \% \mathrm{CI}: 2.19-8.79)$, quarreling with parents $(\mathrm{OR}=$ 3.72, 95\% CI: 2.16-6.41), insomnia (OR = 3.28, 95\% CI: $1.85-$ $5.80)$, feeling anxious ( $\mathrm{OR}=2.62,95 \% \mathrm{CI}: 1.46-4.70)$, previous suicide attempt history $(\mathrm{OR}=2.53,95 \% \mathrm{CI}$ : $1.41-4.54)$, being bullied at school (OR $=2.03,95 \% \mathrm{CI}: 1.15-3.06)$, being attacked by family/teachers/strangers ( $\mathrm{OR}=1.84,95 \% \mathrm{CI}$ : 1.01-3.33), being the only child (OR $=0.48,95 \% \mathrm{CI}: 0.24-0.98)$, and father's emotional warmth $(\mathrm{OR}=0.38,0.20-0.72)$ were associated with SI during COVID-19 lockdown.

\section{DISCUSSION}

The prevalence of SI during the COVID-19 pandemic lockdown was $3 \%$ in this sample of Chinese children and adolescents. Females were more likely to have reported SI than males. Female adolescents, with emptiness from father's emotional warmth to the family, were at much higher risk of having SI during COVID-19 lockdown, while the male adolescents with feelings of depression, insomnia, quarreling with parents during COVID19 , suicidal ideation, or attempt history might associate these with suicidal ideation during COVID-19.

We found that there was an obvious sex difference in suicidal ideation in adolescents, which is consistent with other studies (31). Males and females had common factors for SI. However, there were sex-specific factors associated with SI. Feeling depressed was associated with SI in males rather than in females. Feeling anxious was only associated with SI in females rather than in males. Therefore, given the sex difference, we should pay more attention to different symptomatic manifestations in boys and girls to prevent the occurrence of suicidal behaviors during natural disasters like the COVID-19 pandemic. However, only a few studies are exploring the relationship between mood disorders and suicidal ideation by sexes, and more future studies are needed.

The prevalence of suicidal ideation (3\%) in adolescents was relatively low compared with that in other studies (12.7\%) (10). This may be similar to the result of other studies indicating that the suicide rate in adolescents during the COVID-19 pandemic was not raised, and Tanaka's study showed that the suicide rate declined by $14 \%$ in the first 5 months in Japan $(22,32)$. There are several possible reasons for that. First, home isolation may reduce the chance of negative interpersonal communication with their peers, which may improve the mental health of adolescents (33). Second, according to the results of this study, some adolescents had poor relationships with parents (such as quarreling with parents). This study was conducted when the participants just returned to school and spent more time at school, which might have reduced the conflicts with parents. Third, it is possible that the COVID-19 pandemic lockdown did not have a dramatic impact on suicidal ideation (23-26). Other studies also showed that there was no obvious change of suicidal ideation in adolescents during the COVID-19 pandemic lockdown (32).

Some specific behaviors (quarreling with parents, insomnia, etc.) during COVID-19 may be associated with the onset of SI in adolescents during COVID-19 pandemic lockdown and had negative impacts on adolescents' mental health. Because of the COVID-19 pandemic, it was difficult to seek professional help. In this context, telepsychiatry is a promising way of mental health service delivery to address the issues to enhance the children and youth's ability to cope with stress, alleviate depressed mood, and reduce their risk of suicide $(34,35)$. Given the huge gender difference for suicidal ideation in adolescents, independent predictive models based on gender may be necessary to identify the high-risk individuals for suicidal ideation in adolescents. A finding from our result is that a good fatherly emotional warmth may be an important factor to prevent the occurrence of suicidal ideation in female adolescents.

A suicide prevention system, based on the school-familycommunity joint mechanism for children and adolescents, should be built (36). For the entire society, the suicide prediction 
TABLE 3 | The univariate logistic regression analysis results for suicidal ideation by gender during COVID-19 lockdown in 5,175 Chinese adolescents.

\begin{tabular}{|c|c|c|c|c|}
\hline \multirow[t]{2}{*}{ Items } & \multirow[t]{2}{*}{ Factors } & \multirow[t]{2}{*}{ References } & \multirow{2}{*}{$\begin{array}{c}\text { Male } \\
\text { OR }(95 \% \mathrm{Cl})\end{array}$} & \multirow{2}{*}{$\begin{array}{c}\text { Female } \\
\text { OR }(95 \% \mathrm{Cl})\end{array}$} \\
\hline & & & & \\
\hline \multicolumn{5}{|c|}{ Demographic characteristics } \\
\hline & Age & $\begin{array}{l}\text { Continuous } \\
\text { variable }\end{array}$ & $\begin{array}{c}1.19 \\
(1.02-1.39)\end{array}$ & $\begin{array}{c}0.95 \\
(0.83-1.08)\end{array}$ \\
\hline & One child & Yes/No & $\begin{array}{c}1.02 \\
(0.59-1.78)\end{array}$ & $\begin{array}{c}0.70 \\
(0.40-1.22)\end{array}$ \\
\hline & Residence & Rural/Urban & $\begin{array}{c}1.39 \\
(0.75-2.58)\end{array}$ & $\begin{array}{c}0.66 \\
(0.42-1.02)\end{array}$ \\
\hline & \multirow[t]{2}{*}{$\begin{array}{l}\text { Living } \\
\text { arrangement }\end{array}$} & $\begin{array}{l}\text { Single parent/With } \\
\text { parents }\end{array}$ & $\begin{array}{c}0.88 \\
(0.46-1.66)\end{array}$ & $\begin{array}{c}1.48 \\
(0.90-2.43)\end{array}$ \\
\hline & & $\begin{array}{l}\text { Without parents/ } \\
\text { With parents }\end{array}$ & $\begin{array}{c}0.70 \\
(0.22-2.30)\end{array}$ & $\begin{array}{c}1.66 \\
(0.78-3.54)\end{array}$ \\
\hline & \multirow[t]{2}{*}{ School level } & $\begin{array}{l}\text { Middle school/ } \\
\text { Primary school }\end{array}$ & $\begin{array}{c}1.50 \\
(0.78-2.88)\end{array}$ & $\begin{array}{c}1.09 \\
(0.66-1.82)\end{array}$ \\
\hline & & $\begin{array}{l}\text { High school/ } \\
\text { Primary school }\end{array}$ & $\begin{array}{c}2.17 \\
(0.98-4.82)\end{array}$ & $\begin{array}{c}1.08 \\
(0.54-2.19)\end{array}$ \\
\hline \multicolumn{5}{|c|}{ Specific status during COVID-19 pandemic lockdown } \\
\hline & Feeling depressed & Yes/No & $\begin{array}{c}7.81 \\
(4.46-13.70)\end{array}$ & $\begin{array}{c}40.53 \\
(14.82-110.80)\end{array}$ \\
\hline & Feeling anxious & Yes/No & $\begin{array}{c}12.31 \\
(6.85-22.13)\end{array}$ & $\begin{array}{c}21.85 \\
(11.26-42.41)\end{array}$ \\
\hline & Insomnia & Yes/No & $\begin{array}{c}15.80 \\
(9.37-26.65)\end{array}$ & $\begin{array}{c}17.87 \\
(11.39-28.04)\end{array}$ \\
\hline & $\begin{array}{l}\text { Quarreling with } \\
\text { parents }\end{array}$ & Yes/No & $\begin{array}{c}22.18 \\
(13.09-37.59)\end{array}$ & $\begin{array}{c}18.56 \\
(11.89-28.95)\end{array}$ \\
\hline \multicolumn{5}{|c|}{ Parenting styles } \\
\hline & $\begin{array}{l}\text { Father emotional } \\
\text { warmth }\end{array}$ & Yes/No & $\begin{array}{c}0.30 \\
(0.17-0.51)\end{array}$ & $\begin{array}{c}0.13 \\
(0.08-0.25)\end{array}$ \\
\hline & Father punishment & Yes/No & $\begin{array}{c}3.10 \\
(1.75-5.48)\end{array}$ & $\begin{array}{c}4.51 \\
(2.84-7.16)\end{array}$ \\
\hline & $\begin{array}{l}\text { Father } \\
\text { over-interference }\end{array}$ & Yes/No & $\begin{array}{c}2.20 \\
(1.25-3.90)\end{array}$ & $\begin{array}{c}2.10 \\
(1.35-3.27)\end{array}$ \\
\hline & Father favoring & Yes/No & $\begin{array}{c}1.18 \\
(0.71-1.95)\end{array}$ & $\begin{array}{c}0.72 \\
(0.47-1.09)\end{array}$ \\
\hline & Father rejection & Yes/No & $\begin{array}{c}2.82 \\
(1.64-4.85)\end{array}$ & $\begin{array}{c}3.86 \\
(2.47-6.06)\end{array}$ \\
\hline & $\begin{array}{l}\text { Father } \\
\text { overprotection }\end{array}$ & Yes/No & $\begin{array}{c}2.01 \\
(1.17-3.46)\end{array}$ & $\begin{array}{c}2.20 \\
(1.42-3.39)\end{array}$ \\
\hline & $\begin{array}{l}\text { Mother emotional } \\
\text { warmth }\end{array}$ & Yes/No & $\begin{array}{c}0.39 \\
(0.23-0.65)\end{array}$ & $\begin{array}{c}0.22 \\
(0.13-0.36)\end{array}$ \\
\hline & Moher punishment & Yes/No & $\begin{array}{c}4.37 \\
(2.44-7.83)\end{array}$ & $\begin{array}{c}6.01 \\
(3.64-9.94)\end{array}$ \\
\hline & $\begin{array}{l}\text { Mother } \\
\text { over-interference } \\
\text { and overprotection }\end{array}$ & Yes/No & $\begin{array}{c}2.06 \\
(1.16-3.65)\end{array}$ & $\begin{array}{c}3.52 \\
(2.13-5.82)\end{array}$ \\
\hline & Mother favoring & Yes/No & $\begin{array}{c}1.16 \\
(0.70-1.93)\end{array}$ & $\begin{array}{c}0.85 \\
(0.56-1.29)\end{array}$ \\
\hline & Mother rejection & Yes/No & $\begin{array}{c}2.89 \\
(1.67-5.01)\end{array}$ & $\begin{array}{c}6.17 \\
(3.57-10.65)\end{array}$ \\
\hline \multicolumn{5}{|c|}{ Lifetime severe traumatic events } \\
\hline & $\begin{array}{l}\text { Being bullied at } \\
\text { school }\end{array}$ & Yes/No & $\begin{array}{c}4.49 \\
(2.68-7.52)\end{array}$ & $\begin{array}{c}5.98 \\
(3.87-9.25)\end{array}$ \\
\hline & $\begin{array}{l}\text { Being attacked by } \\
\text { family/ } \\
\text { teachers/strangers }\end{array}$ & Yes/No & $\begin{array}{c}5.84 \\
(3.46-9.86)\end{array}$ & $\begin{array}{c}8.14 \\
(5.19-12.76)\end{array}$ \\
\hline
\end{tabular}

(Continued)
TABLE 3 | Continued

\begin{tabular}{cccc}
\hline Items Factors & References & Male & Female \\
\hline & & OR (95\% Cl) & OR (95\% CI) \\
\hline $\begin{array}{c}\text { Previous suicidal } \\
\text { ideation history }\end{array}$ & Yes/No & 9.35 & 14.44 \\
Previous suicide & Yes/No & $(5.59-15.64)$ & $(8.35-24.96)$ \\
attempt history & & 11.37 & 16.63 \\
Personality trait & & $(6.82-18.97)$ & $(10.40-26.61)$ \\
Emptiness inside & Yes/No & & \\
& & 5.26 & 20.30 \\
& & $(3.19-8.68)$ & $(11.20-36.80)$ \\
\hline
\end{tabular}

TABLE 4 | The gender-specific stepwise logistic regression results for suicidal ideation during COVID-19 lockdown in 5,175 Chinese adolescents.

\begin{tabular}{lcc}
\hline Items Factors & Male & Female \\
\cline { 2 - 3 } & OR $(95 \% \mathrm{Cl})$ & OR $(95 \% \mathrm{Cl})$ \\
\hline
\end{tabular}

Demographic characteristics

$$
\text { One child }
$$

$0.48(0.24-0.98)$

Specific status during COVID-19 pandemic lockdown

$\begin{array}{lcc}\text { Feeling depressed } & 2.26(1.22-4.18) & - \\ \text { Feeling anxious } & - & 2.62(1.46-4.70) \\ \text { Insomnia } & 5.28(2.81-9.93) & 3.27(1.85-5.80) \\ \text { Quarreling with parents } & 9.73(5.38-17.58) & 3.72(2.16-6.41)\end{array}$

Parenting style

Father emotional warmth $\quad-\quad \quad 0.38(0.20-0.72)$

Lifetime severe traumatic events

Being bullied at school

Being attacked by family/

$2.03(1.15-3.60)$

teachers/strangers

Previous suicidal ideation history $2.81(1.30-6.06)$

Previous suicide attempt history $\quad 3.68(1.69-8.03) \quad 2.53(1.41-4.54)$

Personality trait

Emptiness inside

$4.39(2.20-8.79)$

and intervention systems need to be established to identify the high-risk individuals through the system and intervene promptly. In addition, a developmentally-sequenced upstream suicide prevention approach is extremely important (36). Firstly, the parents and the schools should try to eliminate risk factors of suicide such as school bullying and parental abuse. Secondly, we should also pay more attention to strengthening the psychological and behavioral education in children and adolescents to improve mental health, and in minimizing the impact of possible negative events.

Globally, we are still suffering from the COVID-19 pandemic (19) and Murray said that by March 2022, more than 50\% of people in the world will be infected with Omicron, and 80$90 \%$ of them will be asymptomatic (37). At that time, the global immunization level will be at the highest level in history due to continuous vaccination and because of the immunity caused by virus infection. In a few weeks or months, the level of COVID19 spread will decrease (37). Each government should publicize 
epidemic-related policies and promote scientific knowledge on COVID-19 to reduce public panic, especially for adolescents, and reduce the negative impact of rumors (which may increase the risk of suicide), scientifically and correctly arrange online classes, and control the influential impact of home isolation on adolescents $(38,39)$. In the post-pandemic era, the beginning of normal life is also an important period to deal with its sequelae and prevent the potential increase in the suicide rate (23). Changes in the financial conditions of the family (e.g., being laid off), changes in adolescents' social relationships due to home isolation, and discomfort after returning to school may also worsen the mental health of adolescents (40-42). During this period, the school can play an important role in maintaining and improving mental health and preventing suicide in students (43). Adolescents spend more time at school than with their families. Therefore, the school-related department needs to adjust the adolescents' mindset and learning habits to mitigate the adverse impact of the COVID-19 pandemic.

\section{LIMITATIONS}

There were several limitations in this study. First, suicidal ideation and exposures were collected by self-report in this cross-sectional study. Therefore, recall and reporting biases are possible. Second, there were limited correlated factors collected in this study, and some other exposures, such as the history of mental disorders and biological factors, were not collected (44). Third, the participants in this study were only sampled from two cities in Shandong Province, China. Furthermore, because of the relatively low response rate (56\%), this sample may not be representative of the Chinese adolescent population. Finally, in this cross-sectional study, the causal relationships between exposures and suicidal ideation could not be inferred. Cohort studies were needed.

\section{IMPLICATIONS FOR FUTURE RESEARCH}

In our research, a specific status during COVID-19 pandemic lockdown, lifetime severe traumatic events, and parental rearing styles could influence the prevalence of suicidal ideation among adolescents, and there was also a considerable gender difference. At present, there are few studies on the suicide behavior of adolescents during and after the COVID-19 pandemic. Although most of the regions in China have lifted the lockdown measures and returned to normal life, some cities may have to reimplement restrictive measures because of the recurrence of COVID-19. Many countries are still suffering from COVID-19. Therefore, our study generated new knowledge for informing the public health policies and raising awareness about adolescent mental health.

\section{REFERENCES}

1. WHO. Suicide prevention. WHO (2017). Available online at: http://www.who. int/healthinfo/global_burden_disease/estimates/en/index1.html

\section{CONCLUSIONS}

Female adolescents, with a feeling of emptiness from their father's emotional warmth to the family, were at much higher risk of having SI during COVID-19 lockdown. Identifying the predictors of suicide behaviors of different genders is conducive to preventing suicide and is a more effective identification of suicide high-risk groups. Therefore, we have to specify a suicide prevention policy and interventions for adolescents in the pandemic crisis based on gender gaps.

\section{DATA AVAILABILITY STATEMENT}

The raw data supporting the conclusions of this article will be made available by the authors, without undue reservation.

\section{ETHICS STATEMENT}

The studies involving human participants were reviewed and approved by Research Ethics Committee in Jining Medical University. Written informed consent to participate in this study was provided by the participants' legal guardian/next of kin.

\section{AUTHOR CONTRIBUTIONS}

DL, JW, and YL contributed to the study design. LL, DL, SY, and JZhu did the online survey, data collection, and logical check. MC, JZha, YL, and DL analyzed the data. JZhu, BL, FH, and LL wrote this manuscript. DL, YL, and JW revised the manuscript and did the English revision. All authors reviewed and approved the manuscript.

\section{FUNDING}

This study was funded by the Research Fund for Lin He's Academician Workstation of New Medicine and Clinical Translation in Jining Medical University to JZhu (Grant Number: JYHL2019MS05, JYHL2021MS14), Taishan Scholars Project of Shandong Province (tsqn201909145), and Key Research and Development Plan of Jining (Grant Number: 2019SMNS033) to YL, and Innovative Training Program for College Students in Jining Medical University to DL (Grant Number: cx2020009).

\section{ACKNOWLEDGMENTS}

We would like to express our thanks to all the students who had participated in the study.

2. Wasserman D, Cheng Q, Jiang GX. Global suicide rates among young people aged 15-19. World Psychiatry. (2005) 4:114-20.

3. Laido Z, Voracek M, Till B, Pietschnig J, Eisenwort B, Dervic K, et al. Epidemiology of suicide among children and adolescents 
in Austria, 2001-2014. Wien Klin Wochenschr. (2017) 129:1218. doi: 10.1007/s00508-016-1092-8

4. Suokas J, Suominen K, Isometsä E, Ostamo A, Lönnqvist J. Longterm risk factors for suicide mortality after attempted suicide-findings of a 14-year follow-up study. Acta Psychiatr Scand. (2001) 104:11721. doi: 10.1034/j.1600-0447.2001.00243.x

5. Surace T, Fusar-Poli L, Vozza L, Cavone V, Arcidiacono C, Mammano R, et al. Lifetime prevalence of suicidal ideation and suicidal behaviors in gender non-conforming youths: a meta-analysis. Eur Child Adolesc Psychiatry. (2021) 30:1147-61. doi: 10.1007/s00787-020-01508-5

6. Bauman S, Toomey RB, Walker JL. Associations among bullying, cyberbullying, and suicide in high school students. J Adolesc. (2013) 36:341-50. doi: 10.1016/j.adolescence.2012.12.001

7. Geoffroy MC, Boivin M, Arseneault L, Turecki G, Vitaro F, Brendgen M, et al. Associations between peer victimization and suicidal ideation and suicide attempt during adolescence: results from a prospective populationbased birth cohort. J Am Acad Child Adolesc Psychiatry. (2016) 55:99105. doi: 10.1016/j.jaac.2015.11.010

8. Brown J, Cohen P, Johnson JG, Smailes EM. Childhood abuse and neglect: specificity of effects on adolescent and young adult depression and suicidality. J Am Acad Child Adolesc Psychiatry. (1999) 38:14906. doi: 10.1097/00004583-199912000-00009

9. Franklin JC, Ribeiro JD, Fox KR, Bentley KH, Kleiman EM, Huang X, et al. Risk factors for suicidal thoughts and behaviors: a meta-analysis of 50 years of research. Psychol Bull. (2017) 143:187-232. doi: 10.1037/bul0000084

10. Liu XC, Chen H, Liu ZZ, Wang JY, Jia CX. Prevalence of suicidal behaviour and associated factors in a large sample of Chinese adolescents. Epidemiol Psychiatr Sci. (2019) 28:280-9. doi: 10.1017/S2045796017000488

11. Zhang YY, Lei YT, Song Y, Lu RR, Duan JL, Prochaska JJ. Gender differences in suicidal ideation and health-risk behaviors among high school students in Beijing, China. J Glob Health. (2019) 9:010604. doi: 10.7189/jogh.09.010604

12. Keiser O, Spoerri A, Brinkhof MW, Hasse B, Gayet-Ageron A, Tissot F, et al. Suicide in HIV-infected individuals and the general population in Switzerland, 1988-2008. Am J Psychiatry. (2010) 167:143-50. doi: 10.1176/appi.ajp.2009.09050651

13. Tseng MC, Cheng IC, Hu FC. Standardized mortality ratio of inpatient suicide in a general hospital. J Formos Med Assoc. (2011) 110:2679. doi: 10.1016/S0929-6646(11)60040-5

14. Pompili M, Innamorati M, Forte A, Longo L, Mazzetta C, Erbuto D, et al. Insomnia as a predictor of high-lethality suicide attempts. Int J Clin Pract. (2013) 67:1311-6. doi: 10.1111/ijcp.12211

15. Kasen S, Cohen P, Chen H. Developmental course of impulsivity and capability from age 10 to age 25 as related to trajectory of suicide attempt in a community cohort. Suicide Life Threat Behav. (2011) 41:18092. doi: 10.1111/j.1943-278X.2011.00017.x

16. Burke TA, Connolly SL, Hamilton JL, Stange JP, Abramson LY, Alloy LB. Cognitive risk and protective factors for suicidal ideation: a two year longitudinal study in adolescence. J Abnorm Child Psychol. (2016) 44:114560. doi: 10.1007/s10802-015-0104-x

17. Bachmann S. Epidemiology of suicide and the psychiatric perspective. Int $J$ Environ Res. (2018) 15:1425. doi: 10.3390/ijerph15071425

18. WHO. Timeline: WHO's COVID-19 Response. Available online at: https:// www.who.int/emergencies/diseases/novel-coronavirus-2019/interactivetimeline\# event-712021

19. WHO. Coronavirus Disease (COVID-19) Pandemic. Available online at: https://www.who.int/publications/m/item/weekly-epidemiological-updateon-covid-19--11-january-2022

20. Horton R. Offline: 2019-nCoV-"A desperate plea". Lancet. (2020) 395:400. doi: 10.1016/S0140-6736(20)30299-3

21. WHO. Coronavirus disease (COVID-19) advice for the public. Available online at: https://www.who.int/emergencies/diseases/novel-coronavirus2019/advice-for-public2021

22. Tanaka $\mathrm{T}$, Okamoto $\mathrm{S}$. Increase in suicide following an initial decline during the COVID-19 pandemic in Japan. Nature human behaviour. (2021) 5:22938. doi: 10.1038/s41562-020-01042-z

23. Nearchou F, Flinn C, Niland R, Subramaniam SS, Hennessy E. Exploring the impact of COVID-19 on mental health outcomes in children and adolescents: a systematic review. Int J Environ Res Public Health. (2020) 17:8479. doi: 10.3390/ijerph17228479

24. Zhou SJ, Zhang LG, Wang LL, Guo ZC, Wang JQ, Chen JC, et al. Prevalence and socio-demographic correlates of psychological health problems in Chinese adolescents during the outbreak of COVID-19. Eur Child Adolesc Psychiatry. (2020) 29:749-58. doi: 10.1007/s00787-020-01541-4

25. Huckins JF, daSilva AW, Wang W, Hedlund E, Rogers C, Nepal SK, et al. Mental health and behavior of college students during the early phases of the COVID-19 pandemic: longitudinal smartphone and ecological momentary assessment study. J Med Internet Res. (2020) 22:e20185. doi: 10.2196/20185

26. Liu Y, Yue S, Hu X, Zhu J, Wu Z, Wang J, et al. Associations between feelings/behaviors during COVID-19 pandemic lockdown and depression/anxiety after lockdown in a sample of Chinese children and adolescents. J Affect Disord. (2021) 284:98-103. doi: 10.1016/j.jad.2021.02.001

27. Perris C, Jacobsson L, Lindström H, von Knorring L, Perris H. Development of a new inventory assessing memories of parental rearing behaviour. Acta Psychiatr Scand. (1980) 61:265-74. doi: 10.1111/j.1600-0447.1980.tb00581.x

28. Lai S, Su L, Ju W. The factorial structure study on parental rearing scale (EMBU) in adolescents. Strait J Prev Med. (2013).

29. Nock MK, Borges G, Bromet EJ, Cha CB, Kessler RC, Lee S. Suicide and suicidal behavior. Epidemiol Rev. (2008) 30:133-54.

30. STATA. Stata Corporation (Ed.). Stata Statistical Software: Release 151 College Station, TX2015 2015.

31. Ortin A, Elkington KS, Eisenberg R, Miranda R, Canino G, Bird HR, et al. Suicide attempts and course of suicidal ideation among puerto rican early adolescents. J Abnorm Child Psychol. (2019) 47:172334. doi: 10.1007/s10802-019-00554-1

32. Isumi A, Doi S, Yamaoka Y, Takahashi K, Fujiwara T. Do suicide rates in children and adolescents change during school closure in Japan? the acute effect of the first wave of COVID-19 pandemic on child and adolescent mental health. Child Abuse Negl. (2020) 110:104680. doi: 10.1016/j.chiabu.2020.104680

33. Wang G, Zhang Y, Zhao J, Zhang J, Jiang F. Mitigate the effects of home confinement on children during the COVID-19 outbreak. Lancet. (2020) 395:945-7. doi: 10.1016/S0140-6736(20)30547-X

34. King CA, Eisenberg D, Zheng K, Czyz E, Kramer A, Horwitz A, et al. Online suicide risk screening and intervention with college students: a pilot randomized controlled trial. J Consult Clin Psychol. (2015) 83:6306. doi: 10.1037/a0038805

35. Gould MS, Marrocco FA, Kleinman M, Thomas JG, Mostkoff K, Cote J, et al. Evaluating iatrogenic risk of youth suicide screening programs: a randomized controlled trial. JAMA. (2005) 293:1635-43. doi: 10.1001/jama.293.13. 1635

36. Wyman PA, Brown CH, Inman J, Cross W, Schmeelk-Cone K, Guo J, et al. Randomized trial of a gatekeeper program for suicide prevention: 1-year impact on secondary school staff. J Consult Clin Psychol. (2008) 76:10415. doi: $10.1037 / 0022-006 X .76 .1 .104$

37. Murray C. COVID-19 will continue but the end of the pandemic is near. Lancet. (2022) 399:417-9. doi: 10.1016/S0140-6736(22)0 $0100-3$

38. Tasnim S, Hossain MM, Mazumder H. Impact of rumors and misinformation on COVID-19 in social media. J Prev Med Public Health. (2020) 53:1714. doi: 10.3961/jpmph.20.094

39. Pfefferbaum B, Newman E, Nelson SD, Nitiéma P, Pfefferbaum RL, Rahman A. Disaster media coverage and psychological outcomes: descriptive findings in the extant research. Curr Psychiatry Rep. (2014) 16:464. doi: 10.1007/s11920-014-0464-x

40. Schneider W, Waldfogel J, Brooks-Gunn J. The great recession and risk for child abuse and neglect. Child Youth Serv Rev. (2017) 72:7181. doi: 10.1016/j.childyouth.2016.10.016

41. Norman RE, Byambaa M, De R, Butchart A, Scott J, Vos T. The long-term health consequences of child physical abuse, emotional abuse, and neglect: a systematic review and metaanalysis. PLoS Med. (2012) 9:e1001349. doi: 10.1371/journal.pmed.1 001349

42. Wang C, Pan R, Wan X, Tan Y, Xu L, Ho CS, et al. Immediate psychological responses and associated factors during the initial stage of 
the 2019 coronavirus disease (COVID-19) epidemic among the general population in China. Int J Environ. (2020) 17:1729. doi: 10.3390/ijerph170 51729

43. Kidger J, Araya R, Donovan J, Gunnell D. The effect of the school environment on the emotional health of adolescents: a systematic review. Pediatrics. (2012) 129:925-49. doi: 10.1542/peds.2011-2248

44. Cha CB, Franz PJ, E MG, Glenn CR, Kleiman EM, Nock MK. Annual Research Review: Suicide among youth - epidemiology, (potential) etiology, and treatment. J Child Psychol Psychiatry. (2018) 59:460-82. doi: $10.1111 /$ jcpp.12831

Conflict of Interest: The authors declare that the research was conducted in the absence of any commercial or financial relationships that could be construed as a potential conflict ofinterest.
Publisher's Note: All claims expressed in this article are solely those of the authors and do not necessarily represent those of their affiliated organizations, or those of the publisher, the editors and the reviewers. Any product that may be evaluated in this article, or claim that may be made by its manufacturer, is not guaranteed or endorsed by the publisher.

Copyright (C) 2022 Zhu, Li, Hao, Luo, Yue, Zhai, Chen, Liu, Liu and Wang. This is an open-access article distributed under the terms of the Creative Commons Attribution License (CC BY). The use, distribution or reproduction in other forums is permitted, provided the original author(s) and the copyright owner(s) are credited and that the original publication in this journal is cited, in accordance with accepted academic practice. No use, distribution or reproduction is permitted which does not comply with these terms. 